\title{
USO DA PCR PARA DETECÇÃO E IDENTIFICAÇÃO DE MICROBACTÉRIAS A PARTIR DE AMOSTRAS CLÍNICAS DE BOVINOS
}

\author{
(PCR use for detection and identification of mycobacterias from bovine \\ clinical samples)
}

\author{
FUVERKI, R. B. N. 1; MURAKAMI, P. S. ${ }^{2}$; BIONDO, A. W. ${ }^{3}$; BARROS FILHO, I. R. ${ }^{3}$ \\ ${ }^{1}$ Aluna do curso de Graduação em Medicina Veterinária da Universidade Federal do Paraná \\ ${ }^{2}$ Médica Veterinária, Curso de Pós-graduação em Ciências Veterinárias - Universidade Federal do Paraná \\ ${ }^{3}$ Departamento de Medicina Veterinária da Universidade Federal do Paraná
}

\begin{abstract}
RESUMO - A infecção de bovinos por micobactérias, causada principalmente pelo Mycobacterium bovis, tem grande importância devido às enormes perdas econômicas e os riscos à saúde pública relacionados ao seu elevado potencial zoonótico. O objetivo deste trabalho foi testar um protocolo de detecção molecular das subespécies do Complexo Mycobacterium tuberculosis (CMT) a partir de cultura bacteriana. Amostras de órgãos de cinco bovinos suspeitos para a infecção foram submetidas ao cultivo bacteriano e à PCR para a pesquisa de Mycobacterium sp. O DNA bacteriano foi extraído das colônias formadas para a realização de PCR com sete pares de primers: 16S rRNA, Rv0577, IS1561, Rv1510, Rv1970, Rv3877/8 e Rv3120. A reação foi positiva para todos os animais e os resultados mostraram que o perfil da PCR foi adequado para identificar $M$. bovis, estabelecendo especificidade de detecção, enquanto a cultura determina apenas o gênero Mycobacterium. Esse diagnóstico mais específico, sensível e rápido oferece vantagens para o controle e erradicação da tuberculose bovina no Brasil, em particular no diagnóstico postmortem da doença, e contribui com a avaliação de suas implicações na saúde do homem, pelo consumo de alimentos contaminados e por ser um perigo ocupacional em frigoríficos e fazendas.
\end{abstract}

Palavras-chave: PCR; micobactéria; tuberculose; bovino.

ABSTRACT - Mycobacterial infections in bovines, mainly caused by Mycobacterium bovis, have great importance because of economic losses and public health risks related to its elevated zoonotic potential. The objective of this work was to test a molecular protocol for detection of Mycobacterium tuberculosis Complex (MtbC) subspecies from bacterial culture. Organ samples from five bovines with suspicion of infection were submitted to bacterial culture and PCR for Mycobacterium sp. Bacterial DNA was extracted from growing colonies to carry out PCR with seven primer pairs: 16S rRNA, Rv0577, IS1561, Rv1510, Rv1970, Rv3877/8 and Rv3120. Reactions were positive to all tested animals and results showed that the PCR pattern was adequate to identify $M$. bovis, establishing detection specificity while culture only identifies the genre Mycobacterium. This more specific, sensitive and rapid diagnosis offers advantages on bovine tuberculosis eradication and control in Brazil, particularly on post-mortem disease diagnosis, and contributes to the evaluation of its implications on public health by consumption of contaminated food and as an occupational risk in slaughterhouses and farms.

Key words: PCR; micobacterium; tuberculosis; bovine.

\section{INTRODUÇÃO}

A tuberculose bovina é uma doença infectocontagiosa causada pelo Mycobacterium bovis, uma micobactéria da família Mycobacteriaceae que, juntamente com $M$. tuberculosis, $M$. bovis BCG, $M$. africanum, $M$. caprae, $M$. canettii e $M$. microti, forma o Complexo Mycobacterium tuberculosis (CMT) (HUARD et al., 2003). O M. bovis apresenta ocorrência mundial (NEILL et al., 1994) e dados oficiais indicam uma prevalência média deste patógeno em $1,3 \%$ dos rebanhos do território brasileiro (BRASIL, 2006), representando a infecção de mais de 2 milhões de bovinos no país.

A enfermidade nos bovinos apresenta caráter crônico e é caracterizada por lesões granulomatosas localizadas predominantemente no trato respiratório e linfonodos associados (NEILL et al., 1994), caracterizadas por infiltrados de células mononucleares, como macrófagos e linfócitos (POLLOCK et al., 2001). Dentre as principais conseqüências da infec- 
ção, estão a morte de animais, diminuição da eficiência produtiva, eliminação de animais de alto valor zootécnico e condenação de carcaças ao abate, além da perda de credibilidade da propriedade onde ocorreu a infecção, o que acarreta enormes perdas econômicas à produção (BRASIL, 2006).

Além dos prejuízos gerados na produção animal, a tuberculose bovina é uma relevante zoonose cuja transmissão aos humanos pode ocorrer por meio da inalação de partículas infecciosas ou pela ingestão de leite não fervido ou não pasteurizado (THOEN et al., 2006). O M. bovis é classificado como um patógeno de risco 3 para a saúde pública (OIE, 2005) e estima-se que, dentre 100 mil casos de tuberculose em seres humanos descritos anualmente no Brasil, 4 mil estão relacionados à infecção por este microorganismo (LEITE et al., 2003).

O diagnóstico post-mortem da tuberculose causada por M. bovis baseia-se geralmente em exames histológicos e bacteriológicos realizados a partir de amostras teciduais. No entanto, a detecção microscópica de bacilos álcool-ácido resistentes pode falhar em sensibilidade e só funciona em tecidos com concentrações de 10.000 bactérias $/ \mathrm{mL}$ ou superiores. Ainda, estes testes determinam apenas o gênero Mycobacterium. A identificação definitiva da espécie de micobactéria cultivada só é possível por meio de testes bioquímicos e de sensibilidade à drogas (WARDS et al., 1995), os quais demandam um longo tempo e podem apresentar inespecificidade.

A reação em cadeia da polimerase (PCR) tem sido descrita como um método eficiente na determinação da espécie de micobactéria. Pesquisadores têm relatado o uso desta técnica para a detecção de seqüências específicas de $M$. bovis e $M$. tuberculosis, (COUSINS et al., 1991; ROMERO et al., 1999; ZANINI et al., 2001) apresentando boa sensibilidade de determinação a partir de culturas bacterianas. HUARD et al. (2003) desenvolveram um teste de PCR capaz de diferenciar os membros do CMT com base em deleções genômicas, utilizando primers específicos para estas regiões, o que permite a identificação rápida, simples e eficaz da espécie de micobactéria envolvida na infecção.

O objetivo deste trabalho foi testar, aperfeiçoar e padronizar um protocolo de PCR para a diferenciação das espécies de micobactérias do CMT a partir colônias isoladas de cultivos bacterianos, estabelecendo um método rápido e preciso para a classificação e identificação destes microorganismos.

\section{Material e Métodos}

Amostras de órgãos de cinco bovinos que apresentaram suspeita clínica de tuberculose foram avaliadas para a presença de lesões granulomatosas características da infecção. Fragmentos de órgãos contendo nódulos caseosos, como pulmão e linfonodos, foram utilizados para o cultivo bacteriano. As amostras foram homogeneizadas e descontaminadas com solução de $\mathrm{NaOH} 4 \%$, com posterior neutralização com solução de $\mathrm{HCl}$ 1,0 N. Após esse procedimento, os sedimentos gerados foram submetidos à cultura em tubos contendo meio LowesteinJensen, a $37^{\circ} \mathrm{C}$ em estufa bacteriológica.

$\mathrm{O}$ crescimento bacteriano foi acompanhado semanalmente por até 60 dias para a presença de colônias características de micobactérias, de aspecto rugoso e coloração creme-amarelada. Quando presentes, o DNA bacteriano foi extraído utilizando-se o método de choque térmico, o qual consistiu em três ciclos de 30 minutos a $94^{\circ} \mathrm{C}$ e 30 minutos a $-20^{\circ} \mathrm{C}$ para inativação do agente e liberação do material genético.

As reações de amplificação pela PCR foram preparadas com $5 \mu \mathrm{L}$ de DNA extraído, $5 \mu \mathrm{L}$ de tampão 10X Taq DNA polimerase, $\mathrm{MgCl}_{2}$ a $1,5 \mathrm{mM}, 200 \mathrm{mM}$ de cada desoxirribonucleotídeo (dATP, dCTP, dGTP e dTTP), 20 pmoles de cada primer, 0,25 U de enzima Taq polimerase e água ultra pura em quantidade suficiente para completar um volume final de $50 \mu \mathrm{L}$.

O protocolo de amplificação baseou-se no método descrito por HUARD et al. (2003), que permite a tipificação específica das espécies do CMT pelo uso de sete conjuntos de primers que amplificam as regiões 16S rRNA, Rv0577, IS1561, Rv1510, Rv1970, Rv3877/8 e Rv3120, produzindo fragmentos de DNA de 543, 786, 943, 1033, 1116, 999 e 404 pares de base, respectivamente. O programa de amplificação consistiu em um ciclo inicial de desnaturação por 5 minutos a $94^{\circ} \mathrm{C}$, seguido por 35 ciclos de 1 minuto a $94^{\circ} \mathrm{C}, 1$ minuto a $60^{\circ} \mathrm{C}$ e 1 minuto a $72^{\circ} \mathrm{C}$, com ciclo final de extensão por 10 minutos a $72^{\circ} \mathrm{C}$. Os produtos gerados foram submetidos à eletroforese em gel de agarose a 1,5\% corado com brometo de etídio $(0,5 \mathrm{mg} / \mathrm{mL})$, com posterior visualização das bandas em transiluminador de luz ultravioleta. Um marcador de peso molecular de $100 \mathrm{pb}$ foi utilizado como parâmetro de determinação do tamanho das bandas geradas.

\section{Resultados e Discussão}

A cultura em meio Lowestein - Jensen apresentou crescimento bacteriano em todas as amostras, produzindo colônias características do gênero Mycobacterium. A PCR realizada a partir de material genético extraído das colônias também foi positiva para os cinco animais, com amplificação dos fragmentos relativos às regiões $16 \mathrm{~S}$ rRNA, Rv0577, IS1561 e Rv3877/8. De acordo com os painéis de tipificação molecular de micobactérias determinados 
por HUARD et al. (2003), o padrão de amplificação verificado produziu um perfil eletroforético compatível com a identificação de Mycobacterium bovis como a espécie infectante, verificando-se ainda que outros microorganismos do Complexo Mycobacterium tuberculosis não foram detectados nas amostras estudadas. Assim, enquanto a cultura foi capaz de determinar apenas o gênero Mycobacterium, a PCR permitiu estabelecer especificidade de detecção para $M$. bovis, possibilitando estabelecer um perfil epidemiológico da doença entre os indivíduos afetados. Esse resultado está de acordo com os estudos de TIWARI et al. (2007) que demonstraram limitações quanto à especificação do patógeno utilizando apenas o cultivo bacteriano.

A PCR realizada mostrou-se eficaz na determinação da espécie de micobactéria a partir de cepas isoladas de cultivo bacteriano. Em estudo semeIhante, utilizando amostras de órgãos de bovinos provenientes do estado de São Paulo, NASSAR et al. (2007) obtiveram sucesso na identificação de micobactérias do Complexo Mycobacterium tuberculosis utilizando uma PCR-multiplex com os primers JB e primers específicos para o gene que codifica para a pirazinimidase (pncA), o qual permite a diferenciação entre $M$. bovis e $M$. tuberculosis. O grupo obteve $100 \%$ de detecção de $M$. bovis utilizando a PCR a partir das colônias isoladas do meio de cultivo.

MURAKAMI et al. (2007a; 2007b), utilizando o mesmo protocolo de PCR descrito neste trabalho, obtiveram sucesso na detecção de micobactérias em quatis (Nasua nasua) e antas (Tapirus terrestris), determinando a presença de $M$. bovis e $M$. tuberculosis, respectivamente, a partir de colônias isoladas em meio de cultivo. Este resultado demonstra a viabilidade de aplicação da técnica para o controle da enfermidade também em animais selvagens, visto sua importância no risco de manutenção do patógeno em rebanhos e possível transmissão ao homem.

O uso da PCR também é possível para a detecção direta em órgãos com lesões suspeitas de tuberculose demonstrando a versatilidade da técnica, bem como sua eficiência em detectar o microorganismo mesmo em amostras que se apresentam negativas em cultivo bacteriano. TAYLOR et al. (2007) realizaram um estudo de comparação da eficiência de detecção de micobactérias entre a PCR direta em amostras de órgãos e a cultura bacteriana para micobactérias. A PCR foi capaz de detectar o microorganismo em 7 de 9 amostras negativas para o cultivo bacteriano, demonstrando a sensibilidade do método, e mostrou-se ainda mais sensível que a histologia, além de o resultado ser disponibilizado em menor prazo em comparação com as técnicas rotineiramente utilizadas.
A crescente disponibilidade de seqüenciamentos de genomas bacterianos tem proporcionado um melhor levantamento de dados e avanços sem precedentes no diagnóstico, genotipagem e determinação da virulência de patógenos, revolucionando os campos da bacteriologia e doenças infecciosas (FOURNIER et al. 2007). Essas vantagens oferecidas pelo uso de métodos moleculares, como a PCR, proporcionam a melhor interpretação e determinação da epidemiologia de doenças como a tuberculose bovina, contribuindo com a maior acurácia no estabelecimento de dados sobre a enfermidade no país.

A tuberculose bovina ainda representa um importante problema econômico para a agricultura e indústria em muitos países (POLLOCK e NEILL, 2002). A transmissão da doença entre bovinos ocorre principalmente pela excreção respiratória e inalação de $M$. bovis, e sugere-se que a infecção com este microorganismo pode ocorrer mesmo por um único bacilo que alcance a superfície alveolar nos pulmões (MENZIES e NEILL, 2000). Essas informações demonstram a importância da identificação de animais infectados para o controle e erradicação da doença, a qual deve basear-se em um método confiável para a determinação de atitudes precisas frente a rebanhos positivos para a doença.

O projeto teve como base fundamental a importância de se estabelecer um método diagnóstico eficaz, sensível e específico para a tuberculose em bovinos, por ser esta uma doença que tem causado grande impacto na saúde animal e pública do país. $O$ caráter zoonótico da enfermidade oferece enormes riscos principalmente a pacientes imunocomprometidos, seja por quimioterapia, transplantes de órgãos, ou portadores do vírus da AIDS (THOEN et al., 2006). EVANS et al. (2007) relataram a transmissão entre seres humanos da tuberculose causada por $M$. bovis, o que representa um agravo à disseminação do patógeno e ao risco zoonótico. Existe ainda o risco ocupacional da doença, comprometendo a saúde de trabalhadores que têm grande chance de contato com o microorganismo (DE LA RUA-DOMENECH, 2006), como funcionários de frigoríficos e propriedades rurais. A possibilidade de transmissão do agente através de produtos alimentícios derivados de bovinos (ETTER et al., 2006) também é outro fator de risco que colabora com a crescente necessidade de se desenvolver uma metodologia segura e eficiente na deteç̧ão de Mycobacterium spp. a partir de amostras clínicas de bovinos.

\section{CONCLUSÕES}

O diagnóstico por meio da pcr, sensível e rápido de Mycobacterium spp; pode ser utilizado para 
ações pontuais da defesa sanitária animal com o intuito de controlar e erradicar a doença no país, em particular no rastreamento de produtos derivados de bovinos e no diagnóstico post-mortem da doença. Ainda, a determinação da espécie de micobactéria contribui com o estabelecimento da epidemiologia molecular da doença no país, colaborando assim com a efetividade do Programa Nacional de Controle e Erradicação da Brucelose e Tuberculose. Os resultados demonstraram que a PCR é um método adequado para identificar amostras de $M$. bovis a partir de colônias isoladas em meio de cultivo diagnóstico no Brasil, e a sua implantação em centros de diagnóstico é de grande valia, servindo como eficaz ferramenta de identificação de focos da infecção em rebanhos nacionais. Em conclusão, o uso da PCR torna possível o diagnóstico definitivo em amostras post-mortem e em produtos de origem animal, possibilitando atitudes sanitárias em menor prazo frente aos bovinos infectados e à população humana sob risco de infecção.

\section{REFERÊNCIAS}

BRASIL. Ministério da Agricultura, Pecuária e Abastecimento. Secretária de Defesa AgropecuáriaDepartamento de Saúde Animal. Programa Nacional de Controle e Erradicação da Brucelose e da Tuberculose Animal (Pncebt). Brasília: MAPA/SDA/ DSA, 2006, 188p.

COUSINS, D.V.; WILTON, S.D.; FRANCIS, B. R. Use of DNA amplífication for the rapid identification of Mycobacterium bovis. Veterinary Microbiology, v. 27, p. $187-195,1991$.

DE LARUA-DOMENECH, R. Human Mycobacterium bovis infection in the United Kingdom: Incidence, risks, control measures and review of the zoonotic aspects of bovine tuberculosis. Tuberculosis, v. 86, n. 2, p. 77-109, 2006.

ETTER, E.; DONADO, P.; JORI, F.; CARON, A.; GOUTARD, F.; ROGER, F. Risk analisys and bovine tuberculosis, a re-emerging zoonosis. Annals of the New York Academy of Sciences, v. 1081, p. 61-73, 2006.
EVANS, J. T.; SMITH, E. G.;BANERJEE, A.; SMITH, R. M. M.; DALE, J.; INNES, J. A.; HUNT, D.; TWEDDELL, A.; WOOD, A.; ANDERSON, C.; HEWINSON, R. G.; SMITH, N.H.; HAWKEY, P. M.; SONNENBERG, P. Cluster os human tuberculosis caused by Mycobacterium bovis: evidence for person-to-person transmission un the UK. The Lancet, v. 369, n. 956, p. 1270-1276, 2007.

FOURNIER, P. E.; DRANCOURT, M.; RAOULT, D. Bacterial genome sequencing and its use in infectious diseases. The Lancet Infectious Diseases, v. 7, n.11, p.711-723, 2007.

HUARD, R. C.; LAZZARINI, L. C. O.; BUTLER, W. R.; VAN SOOLINGEN, D.; HO, J. L. PCR-based method to differentiate the subspecies of the Mycobacterium tuberculosis complex on the basis of genomic deletions. Journal of Clinical Microbiology, v. 4, p.1637-1650, 2003.

LEITE, C. Q. F.; ANNO, I. S.; LEITE, S. R. A.; ROXO, E.; MORLOCK, G. P.; COOKSEY, R. C. Isolation and identification of mycobacteria from livestock specimens and Milk obtained in Brazil. Memórias do Instituto Oswaldo Cruz, v. 98, n. 3, p. 319-323, 2003.

MENZIES, F. D.; NEILL, S. D. Cattle-to-cattle transmission of bovine tuberculosis. The Veterinary Journal, v. 160, p. 92-106, 2000.

MURAKAMI, P. M.; BROCKELT, S. R.; BIESDORF, S. M; NAKATANI, S. M.; RIEDIGER, I. N.; FUVERKI, R. B. N.; BIAVA, J.; VILANI, R. G. O. C.; BARROS FILHO, I. R.; BIONDO, A. W. Diagnóstico molecular de Mycobacterium sp. em quatis (Nasua nasua) do Centro de Triagem de Animais Silvestres de Tijucas do Sul, PR. In: Anais do II Congresso de Saúde Pública, Fortaleza, Brasil, 2007a.

MURAKAMI, P. M.; JAVOROUSKY, M. L.; BONAT, M.; LACERDA, O.; BROCKELT, S. R.; BIESDORF, S. M; NAKATANI, S. M.; RIEDIGER, I. N.; FUVERKI, R. B. N.; BIAVA, J.; VILANI, R. G. O. C.; BARROS FILHO, I. R.; CAVAZZANI, L. F.; BIONDO, A. W. Molecular diagnosis of Mycobacterium tuberculosis in tapirs (Tapirus terrestris) from the Curitiba Zoo, Paraná. In: Anais do Congresso "Todos pela Conservação", São Paulo, Brasil, n. 365, p. 68, 2007b. 
NASSAR, A. F.; MIYASHIRO, S.; OLIVEIRA, C. G.; PACHECO, W. A.; OGATA, R. A. Isolation and identification of bovine tuberculosis in a brazilian herd (São Paulo). Memórias do Instituo Oswaldo Cruz, v. 102, n. 5, p. 639-642, 2007.

NEILL, S. D.; POLLOCK, J. M.; BRYSON, D. B.; HANNA, J. Pathogenesis of Mycobacterium bovis infection in cattle. Veterinary Microbiology, v. 40, p. 41-52, 1994.

OIE - Organização Internacional de Epizootias, 2005. Bovine tuberculosis. Disponível em: < http:// www.cfsph. iastate.edu / Factsheets / pdfs / bovine _tuberculosis . pdf>. Acesso em: 07nov2007.

POLLOCK, J.M.; NEILL,S.D. Mycobacterium bovis infection and tuberculosis in cattle. The Veterinary Journal, v. 163, p. 115-127, 2002.

POLLOCK, J. M.; MCNAIR, J.; WELSH, M. D.; GIRVIN, R. M.; KENNEDY, H. E.; MACKIE, D. P.; NEILL, S. D. Immune responses in bovine tuberculosis. Tuberculosis, v. 81 , p. 103-107, 2001.

ROMERO, R. E.; GARZON, D. L.; MEJIA, G. A.; MONROY, W.; PATARROYO, M. E.; MURILLO, L. A. Identification of Mycobacterium bovis in bovine clinical samples by PCR species-specific primers. Canadian Journal of Veterinary Research, v. 63, p. 101-106, 1999.

TAYLOR, G. M.; WORTH, D. R.; PALMER, S.; JAHANS, K.; HEWINSON, R. G. Rapid detection of Mycobacterium bovis DNA in cattle lymph nodes with visible lesions using PCR. BMC Veterinary Research, v. 3, p. 3-12, 2007.

TIWARI, R. P.; HATTIKUDUR, N. S.; BHARMAL, R. N.; KARTIKEYAN, S.; DESHMUKH, N. M.; BISEN, P. S. Modern approaches to a rapid diagnosis of tuberculosis: promises and challenges ahead. Tuberculosis, v. 87, n. 3, p. 193 - 201, 2007.

THOEN,C.; LOBUE, P.; DE KANTOR, I. The importance of Micobacterium bovis as a zoonosis. Veterinary Microbiology, v.112, p. 339-345, 2006.
WARDS, B. J.; COLLINS, D. M.; de LISLE, G. W. Detection of Mycobacterium bovis in tissues by polimerase chain reation. Veterinary Microbiology, v. 43, p. 227-240, 1995.

ZANINI, M. S.; MOREIRA, E. C.; LOPES, M. T. P.; OLIVEIRA, R. S.; LEÃO, S. C.; FIORAVANTE, R. L.; ROXO, E.; ZUMARRAGA, M.; ROMANO, M. I.; CATALDI, A.; SALAS, C. E. Mycobacterium bovis polymerase chain reaction identification in bovine lynphnode biopsies and genotyping in isolates from southeast Brazil by apolygotyping and restriction fragment lenght polymorphism. Memorias do Instituto Osvaldo Cruz, v. 96, p. 809-813, 2001.

Recebido para publicação:

$12 / 12 / 2007$ Aprovado: 05/05/2008 